\title{
Constructing an assessment framework for the quality of asthma smartphone applications
}

\author{
Zhifang Guan, Liu Sun, Qian Xiao and Yanling Wang ${ }^{*}$ (1)
}

\begin{abstract}
Background: Enhancing the self-management capability of asthma patients can improve their level of asthma control. Although the use of mobile health technology among asthmatics to facilitate self-management has become a growing area of research, studies of mobile health applications (apps), especially for evaluating indicators of asthma apps, are deficient in scope. This study aimed to develop a reliable framework to assess asthma apps (i.e., content and behavior change strategies) using the Delphi survey technique.

Methods: An initial list of quality rating criteria for asthma apps was derived from reviewing the literature and experts in the fields of respiratory disease and nursing informatics rated the items on the list in three rounds. The weights of items were determined employing an analytic hierarchy process (AHP).

Results: Sixty-two items were retained within 10 domains. Consensus was reached on 32 items concerning asthma self-management education, 25 items concerning behavioral change strategies, and five items concerning principles for app design. There was moderate agreement among participants across all items in round three. The weights of the dimensions, sub-dimensions, and items ranged from 0.049 to $0.203,0.138$ to 1.000 , and 0.064 to 1.000 , respectively. All random consistency ratio values were less than 0.1 .
\end{abstract}

Conclusions: Asthma self-management education and strategies are essential parts to support self-management for patients. This analysis provides evidence of evaluating criteria for apps targeting chronic and common diseases.

Keywords: Asthma, Apps, Self-management, Evaluation index, Delphi survey

\section{Background}

Asthma is the most common chronic respiratory disease affecting up to $18 \%$ of the people in the world [1]. An estimated 334 million people suffer from asthma [2], and the disease is uncontrolled for many patients in developing and undeveloped countries. For example, in Asia, asthma was controlled in only $2.5 \%$ of the affected population in 2006 [3], burdening patients, families, governments, and healthcare systems [4]. To prevent the processes of asthma, a myriad of effective measures have been identified and international guidelines concerning asthma self-management education have been promulgated, that have had a positive effect on outcomes [5].

Asthma causes long-term inflammation in the lungs that requires patients to modify their lifestyles-such as

\footnotetext{
*Correspondence: wangyanling_eliza@126.com

Capital Medical University, School of Nursing, Beijing, China
}

smoking cessation and the avoidance of passive smoke. Therefore, healthcare providers at the point of care should be skilled and experienced in asthma selfmanagement education and behavior change strategies to improve the quality-of-life of asthma sufferers [6]. Germane to asthma self-management education, numerous randomized controlled trials have demonstrated positive changes in patient-centered outcomes related to education and behavioral interventions [7]. Nevertheless, many healthcare providers lack training in selfmanagement education and many have little time or motivation to help patients develop those skills [8].

As the use of mobile devices and smartphones becomes more ubiquitous, patients could make full use of applications (apps) on these devices for asthma selfmanagement [8]. Currently, apps on mobile devices can enable patients to monitor and manage the disease,

(c) The Author(s). 2019 Open Access This article is distributed under the terms of the Creative Commons Attribution 4.0 International License (http://creativecommons.org/licenses/by/4.0/), which permits unrestricted use, distribution, and reproduction in any medium, provided you give appropriate credit to the original author(s) and the source, provide a link to the Creative Commons license, and indicate if changes were made. The Creative Commons Public Domain Dedication waiver (http://creativecommons.org/publicdomain/zero/1.0/) applies to the data made available in this article, unless otherwise stated. 
obtain education, and improve health behavior. Communication among users or with practitioners can become more frequent with mHealth apps and mobile technology [9]. Therefore, healthcare providers should assist asthmatics in identifying mHealth smartphone apps that help manage the disease and enable them to provide detailed and personalized feedback to patients at any time [10]. For example, the China Internet Network Information Center (CNNIC) released its annual report on the development of the Internet in China in June 2017, indicating China had 751 million Internet users and 724 million mobile Internet users, an increase of 28.3 million from 2016 [11]. Two hundred fifty-nine thousand mHealth apps were available on major app stores worldwide [12]. These apps have the potential to help a variety of patients improve self-management of their long-term, chronic conditions [13].

Although mHealth apps hold promise and provide advantages for improving health, their quality and suitability for use in clinical practice must be evaluated. Currently, user-based rating systems are provided by the Apple App Store and Google Play (previously Android Market). These rating systems allow users to rank apps from one to five stars in terms of criteria such as usability; however, the validity and reliability of these rating systems and ratings have yet to be reported [14]. As long as the mHealth apps available on these platforms do not make misleading advertising claims and protects the data and identities of the users, they can provide benefit to potential users with chronic diseases [15]. Nevertheless, mHealth apps have rarely adhered to evidence-based principles and peer-reviewed guidelines [16]. For example, Rosser and Eccleston reviewed apps for pain management and report that $86 \%$ of the apps indicated no involvement of medical professionals [17]. Moreover, the health information delivered on mHealth apps frequently lacks scientific basis and validity [18]. Furthermore, malfunctions, breaches of patient confidentiality, and conflicts of interests involving apps all conspire against the provision of safe patient care [19]. The staggering number and variety of these mHealth apps makes it difficult for clinicians and the public to identify which of the apps are the safest and most effective [20, 21]. In addition, a lack of standardized rating tools further limits the potential use of apps as part of legitimate healthy lifestyle interventions. Although several assessment frameworks have been published to help rate app quality (e.g., Huckvale et al. developed criteria to assess the content quality of asthma apps [22], and Tinschert et al. applied review frameworks [i.e., behavior change techniques and information] to investigate the potential of asthma apps for self-management [23]), no single instrument addresses the unique combination of information and behavior strategies necessary for asthma patients to effectively self-manage their care.
Clearly, an objective and reliable instrument is necessary to rate the quality of mHealth apps-especially those related to asthma. This instrument initially could be used by researchers and later be made available to app developers and health professionals. This study aimed to develop a reliable and multidimensional index system for rating the mHealth apps for asthma patients that would satisfy the following criteria: (1) provides evidence for patients with asthma and healthcare providers for choosing apps to treat asthma; (2) presents a reference for developers to design asthma apps systematically and scientifically; (3) contributes to improving quality evaluation standards for apps targeting chronic and common diseases.

\section{Methods}

Study design

To develop a reliable and multidimensional assessment framework for rating the mHealth apps for asthma patients, a three round Delphi survey was conducted using paper-based forms. Experts were asked to indicate the importance of each item based on a 5-point Likert scale from 1 (i.e., not important) to 5 (i.e., extremely important) [24]. Experts provided feedback between each round of the survey and results were summarized. In a Delphi survey, the multi-round iterative process generally continues until the experts arrive at a common understanding of the qualitative data [25].

No standard methods are available to determine consensus levels [26]. In this study, consensus between participants was measured using the mean importance rating, the coefficient of variation $(\mathrm{CV}$ is the ratio of the standard deviation of the responses of the experts on a specific item to its corresponding mean average), and the percentage important (defined as the percentage of respondents who rated a particular item as extremely important) [27]. Items were either retained, removed, modified, or added in each Delphi round, based on this standard to reach consensus. The criterion of the mean importance rating and the percentage important is the mean of all items minus their standard deviation, and an item whose score greater than or equal to the criterion is preserved. The criterion of the coefficient of variation is all items' mean plus standard deviation, keeping the items whose score below or equal to the criterion. When item failed to meet either of the above criteria, were deleted. When the item meets one or two criteria, the decision was made after the discussion of a research group consisting of one associate professor, one university lecturer and three master degree students. Data analysis was performed by two of the authors.

After two rounds of the Delphi survey, the relative importance of each item (e.g., Asthma is a chronic respiratory disease, together with airway hyperresponsiveness 
and airway inflammation, and Asthma cannot be cured, but can be effectively controlled through effective management) was calculated. The analytic hierarchy process (AHP) fundamental scale developed by Saaty for pairwise comparisons was then used to construct the judgment matrix to calculate the weight of each item [28].

In the study, each participant compared all criteria pairwise with each other using a scale ranging from 1 to 9 to 1 . For each pair, participants had to select which was more important, see Fig. 1. After collecting the questionnaires, the AHP module matrix written with Excel was utilized for data analysis.

In addition, a consistency test was conducted of the judgment matrix. When the random consistency ratio (CR) was less than 0.1, then the judgment matrices were considered acceptable.

The CR coefficient is calculated as follows [29].

$\mathrm{CI}$ represents the consistency index, and RCI represents random consistency index, which was used to modify the CI value (if $n>2$ ). $n$ means the order of the matrix.

$$
\mathrm{CI}=\left(\lambda_{\max }-\mathrm{n}\right) /(\mathrm{n}-1)
$$

$\lambda_{\max }$ means an approximation of the maximum eigenvalue of the judgement matrix.

The CR coefficient is obtained by dividing the $\mathrm{CI}$ value by RCI. The value of RCI of the reciprocal matrix of 1-9 orders is given in Table 1.

$$
\mathrm{CR}=\mathrm{CI} / \mathrm{RCI}(2)
$$

\section{Participant recruitment}

Participants were active in the field of respiratory disease having expertise in asthma management. Experts were identified from Beijing and Tianjin working in general hospital or medical university. Experts were identified according to the following criteria: (1) they had to be engaged in the field of respiratory for more than 5 years; (2) they had to hold intermediate professional titles and a college degree or graduate degree in a respiratory field;
Table 1 The value of random consistency index $(R C l)$ of the reciprocal matrix of 1-9 orders

\begin{tabular}{llllllllll}
\hline Matrix order & 1 & 2 & 3 & 4 & 5 & 6 & 7 & 8 & 9 \\
\hline $\mathrm{RCl}$ & 0 & 0 & 0.58 & 0.90 & 1.12 & 1.24 & 1.32 & 1.41 & 1.45 \\
\hline
\end{tabular}

(3) they had to be willing take part in all rounds of the Delphi survey.

\section{Procedure \\ Developing the initial index system}

The asthma self-management education and behavior change techniques (BCT) and corresponding items to be evaluated through the Delphi survey were identified through (1) a content analysis of 110 asthma apps from the Apple App Store and Google Play that covered selfmanagement education and functions [30] and (2) a review of the relevant literature.

For the literature review, major databases (i.e., PubMed, Ovid, EBSCO, Elsevier, SpringerLink, SinoMed, China National Knowledge Infrastructure [CNKI], and WanFang) were searched using the keywords asthma and self-management or behavior change techniques or mobile app* and evaluate* or mobile app* and assess* between the date January 2013 and October 2017. There were 10,545 articles retrieved, 6363 were removed as duplicates, and after initial screening of title and abstract, only 734 articles that reported asthma self-management education, behavior change techniques and evaluation instrument of apps were included. After reading their full text, 14 major relevant articles were identified.

App assessment items were extracted by analyzing the major relevant literature $[2,6,9,23,31-40]$ by two authors, who then drafted a set of provisional dimensions for the items and sorted them by dimension. A total of 105 items were identified. That fell into 10 major dimensions: (1) goals and planning, (2) feedback and monitoring, (3) shaping knowledge, (4) social support, (5) reward and threat, (6) natural consequences, (7) improving the compliance, (8) asthma information, (9) patient skills training, and (10) non-pharmacological interventions. After removing redundant items, 87 items

\section{$\begin{array}{lllllllllllllllllll}\text { Dimension } & 1 & 2 & 3 & 4 & 5 & 6 & 7 & 8 & 9 & 8 & 7 & 6 & 5 & 4 & 3 & 2 & 1 & \text { Dimension }\end{array}$}
Asthma
Shaping
knowledge

Fig. 1 A sample question of pairwise comparisons in the questionnaire. 1: Equal importance; 3: Moderate importance of one over another; 5: Essential or strong importance; 7: Very strong importance; 9: Extreme importance; 2, 4, 6, 8: Intermediate values between the two adjacent judgements 
Table 2 The items in the questionnaires of round 1 Delphi survey

Dimensions

1. Goals and planning

2. Feedback and monitoring

3. Shaping knowledge

4. Social support

5. Reward and threat

6. Natural consequences

7. Improving the compliance

8. Asthma information

9. Patient skills training

10. Non-pharmacological interventions

Sub- dimensions 1.1 Goal setting (outcome/behavior)

1.2 Asthma action plans

2.1 Self-monitoring of behavior

2.2 Self-monitoring of outcomes of behavior

2.3 Feedback

3.1 Demonstration of the behavior

3.2 Behavior substitution

4.1 Practical social support

4.2 Emotional support

5.1 Social reward

5.2 Threat

6.1 Information about health consequences

6.2 Salience of consequences

7.1 Prompts

7.2 Regulation

8.1 The nature of asthma

8.2 Asthma medication

8.3 Management of asthma exacerbation

8.4 Management of comorbidities

9.1 Peak flow meter usage

9.2 Inhaler technique

10.1 Identifying and avoiding risk factors

10.2 Good life style

Items
1.1.1 Ask patients to reflect on what they would consider as good asthma control

1.1.2 The purpose of asthma control is to have good asthma control and no limited activities

1.1.3 Set specific behavior goals in terms of the behavior to be achieved

1.1.4 State the factors that influence the behavior, and generate strategies that overcome barriers and increase facilitators

1.1.5 Set goals in terms of a positive outcome

1.1.6 Re-set new goals in light of achievement

1.2.1 Patient should be provided with an asthma
Table 2 The items in the questionnaires of round 1 Delphi survey (Continued)

action plan, and updated in time

1.2.2 State that asthma action plan helps patient to recognize and response appropriately to worsening asthma

1.2.3 Set detailed planning of performance of the behavior

1.2.4 Patients need to affirm commitment to change the behavior

2.1.1 States that the valid approaches for self-monitoring are PEF monitoring and symptom recognition

2.1.2 Provides reminders to monitor PEF everyday, and can record details

2.1.3 Provides reminders to monitor symptoms everyday, and can record details

2.1.4 Provides a diary to record medication

2.1.5 Provides a diary to record patients' feeling

2.1.5 Provides a diary to record return visit

2.2.1 Provides a diary to record lung function test

2.2.2 Provides a diary to record worsening asthma-related events

2.2.3 Provides a diary to record factors related to worsening asthma, such as weather

2.2.4 Provides asthma assessment tools

2.3.1 Monitors and provides informative or evaluative feedback on performance of the behavior

2.3.2 Provide professional feedback information based on patients' inhaler technique

2.3.3 Provides evaluative feedback on asthma status

2.3.4 Provides informative feedback on asthma severity based on PEF values

2.3.5 Generates PEF/symptoms summary visualization

2.3.6 Provides result feedback through connecting medical devices

3.1.1 Provide video tutorials or animations of peak flow meter use

3.1.2 Provide video tutorials or animations of inhaler devices use

3.1.3 Provides video tutorials or animations to display instructions of spacer for patients

3.2.1 States wanted or neutral behavior to substitute the unwanted behavior

3.2.2 States repetition of the wanted behavior

4.1.1 Allows establishing a cooperative relationship between doctors and patients

4.1.2 Allows setting goals by patients and doctors

4.1.3 Provides video tutorials or animations about asthma information introduced by medical workers

4.1.4 Allows users to share health data with medical workers through email

4.1.5 Allows patients to communicate with patients with controlled asthma 
Table 2 The items in the questionnaires of round 1 Delphi survey (Continued)

4.2.1 States that friends, relatives and medical workers should provide emotional support

4.2.2 Provides encouragement and consultation from friends, relatives and medical workers

4.2.3 Provides self-incentive in performing the behavior

5.1.1 Send incentive information if there has been progress in performing the behavior

5.2.1 Do not send incentive information if patients with unwanted behavior

6.1.1 Provides information about health consequences of performing the behavior

6.1.2 Provides information about social and environmental consequences of performing the behavior

6.2.1 Provides methods specifically designed to emphasize the consequences of performing the behavior

7.1.1 Set environmental or social stimulus in order to prompt the behavior

7.1.2 Allows users to set reminder for medication/return visit

7.1.3 Provides reminders for checking inhaler to ensure inhalers are not empty

7.1.4 Provides reminders for checking inhaler to ensure inhalers are in date

7.2.1 Provides stress-reduction strategies to prevent symptoms from worsening

7.2.2 States the importance of avoiding use of multiple different inhaler types

8.1.1 Asthma is a chronic respiratory disease, together with airway hyperresponsiveness and airway inflammation

8.1.2 Asthma is caused by a combination of endogenous (genetic) and external (environment) causes.

8.1.3 Respiratory symptoms of asthma are wheeze, shortness of breath, chest tightness and cough

8.1.4 Asthma severity can be assessed as mild asthma, moderate asthma, and severe asthma

8.1.5 Asthma cannot be cured, but can be effectively controlled through effective management.

8.1.6 Early controller treatment of asthma is critical to achieving optimal outcomes

8.2.1 Asthma medications include controller medications and reliever medications

8.2.2 Controller medications can be used to reduce airway inflammation, control symptoms, and reduce future risks

8.2.3 Controller medications should be used for regular

8.2.4 Reliever medications are used to relief breakthrough symptoms

8.2.5 Reliever medications are used as needed
Table 2 The items in the questionnaires of round 1 Delphi survey (Continued)

8.2.6 Local side-effects of ICS include oral thrush and dysphonia

8.2.7 Side-effects of oral corticosteroids include osteoporosis, hypertension, and diabetes, etc.

8.2.8 Side-effects of $\beta_{2}$-agoinsts include tachycardia and tremor

8.2.9 Patients need to carry asthma reliever medications (such as Ventolin solution) with them in case of emergency

8.3.1 Early signs and symptoms of worsening asthma are sneezing, runny nose, dry cough, shortness of breath, and chest tightness, etc.

8.3.2 Symptoms of asthma exacerbations are a progressive increase in symptoms of shortness of breath, cough, wheezing or chest tightness

8.3.3 It is important to adjust treatment plan and went to see the doctor in time

8.3.4 Patients were removed from the allergen environment, inhale $\beta_{2}$ agonist, and went to see the doctor in time

8.4.1 Complications should be treated, such as rhinitis, sinusitis, and symptomatic gastroesophageal reflux disease

8.4.2 Obese patient should lose weight

9.1.1 Operational criteria of peak expiratory flow meter: taking a deep breath; sealing your mouth tightly around the mouthpiece; blowing as hard and as fast as you soon; checking the number, re-setting the pointer to zero; and repeating two more times

9.1.2 A peak flow meter is used for monitoring lung function changes in patients

9.1.3 Patients should use the same meter each time

9.2.1 Patients should be encouraged to participate in the choice of inhaler device

9.2.2 Emphasizes the importance of correct inhaler technique

9.2.3 States that patients should breathe deeply and hold their breath for a few seconds for effective use of inhaler devices

9.2.4 Patients should rinse and spit the mouse after using the inhaled hormone

9.2.5 States that appropriate use of spacer device can improve effect and reduce adverse drug reactions

10.1.1 States identifying risk factors that make asthma worse

10.1.2 States the importance of avoidance of environmental smoke exposure

10.1.3 States the importance of avoidance of occupational exposures

10.1.4 States the importance of avoidance of medications that may make asthma worse

10.1.5 States the importance of avoidance of allergens exposure 
Table 2 The items in the questionnaires of round 1 Delphi survey (Continued)

10.2.1 States the importance of consuming a

diet high in fruit and vegetables

10.2.2 States the importance of avoidance of indoor air pollutants

10.2.3 States the importance of engaging in regular physical activity

remained, which the authors then grouped into 23 subdimensions, defining the 10 major dimensions. They were (1) goal setting (outcome/behavior), (2) asthma action plans, (3) self-monitoring of behavior, (4) selfmonitoring of outcomes of behavior, (5) feedback, (6) demonstration of the behavior, (7) behavior substitution, (8) practical social support, (9) emotional support, (10) social reward, (11) threat, (12) information about health consequences, (13) salience of consequences, (14) prompts. (15) regulation, (16) the nature of asthma, (17) asthma medication, (18) management of asthma exacerbation, (19) management of comorbidities, (20) peak flow meter usage, (21) inhaler technique, (22) identifying and avoiding risk factors, (23) good life style. The research group ensure that the survey questionnaire did not include items that were difficult to understand or repetitive. The preliminary list of proposed items underwent a process of revision and adaptation to reach a definitive version that was approved by all authors. The questionnaire was sent to each expert who agreed to participate in the study and the Delphi process was explained to these participants. The original list appears in Table 2.

\section{Round 1 of Delphi survey}

In round one of the Delphi survey, in November, 2017, a total of 25 experts agreed to participate in the Delphi survey. They represented six hospitals and/or academic institutions in Beijing and Tianjin, including Capital Medical University School of Nursing, Beijing Chaoyang Hospital affiliated to Capital Medical University, Xuanwu Hospital affiliated to Capital Medical University, Beijing Children's Hospital affiliated to Capital Medical University, China-Japan Friendship Hospital in Beijing, and Tianjin Medical University General Hospital. All expert participants in round one were female whose ages ranging from 31 to 55 years (mean $=42.28$; $\mathrm{SD}=6.58)$. Participants were drawn from three main occupational groups: nurse educators in higher education, clinical head nurses, and respiratory physicians.

The first-round questionnaire contained 10 dimensions, 23 sub-dimensions, and 87 items. In addition, the questionnaire contained of 50 items related to behavioral change strategies and 37 items related to asthma selfmanagement education.
The first section of the first-round questionnaire (1) describes the background and objectives of the study and (2) specifies the deadline for returning the completed questionnaire. The second section elicits the opinions of experts concerning not only the revision, addition, and/or deletion of any items, but also the importance of each item based on a 5-point Likert scale. In addition, participants were given an option to suggest additional items. The third section elicited demographic information from the participants, which included professional background (i.e., years engaged in work, educational background, professional title, and affiliation). In this section, the expert degree of authority also was measured. The authority coefficient $\left(C_{r}\right)$, in relation to the participants' technical ability to evaluate the items, was determined by two factors: the participants' familiarity with the items $\left(C_{s}\right)$ and the judgment criteria for the items $\left(C_{a}\right)$ [41]. Familiarity with items was measured on a 5-point Likert Scale in the following order and score: unfamiliar (0), somewhat unfamiliar (0.2), somewhat familiar (0.5), very familiar (0.8), extremely familiar (1). The judgment criteria for the items encompassed parameters such as experience in asthma self-management, theoretical analysis of items, knowledge of the literature, and instinct. A scoring system was used to rate the experts' criterion for their judgments (see Table 3) [42], and the rating was done by the participants. Informed consent was obtained from each participant once they accepted the invitation to participate.

\section{Round 2 of Delphi survey-determining the weight of each item through AHP}

The second round of the Delphi survey ended in January, 2018 with 24 experts participating. Of these, 20 participated in the first-round and four new experts were added. The five participants who dropped out after the first round did so because of vacations. The secondround questionnaires were based on the results of the first-round, according to both the agreement on each item and the suggestions of experts. Participants were required to (1) re-rate the importance of the items on the questionnaire regarding the apps and (2) provide additional edits, revisions, suggestions, comments, and/ or questions. The three sections of the round two

Table 3 Criterion for judgment and scoring system

\begin{tabular}{|c|c|c|c|}
\hline \multirow[t]{3}{*}{ Judgment Criterion } & \multicolumn{3}{|c|}{ The Degree of Impact on Experts' Judgement } \\
\hline & Large & Medium & Small \\
\hline & Impact & Impact & Impact \\
\hline Experience & 0.5 & 0.4 & 0.3 \\
\hline Theoretical analysis & 0.3 & 0.2 & 0.1 \\
\hline Knowledge of literature & 0.1 & 0.08 & 0.05 \\
\hline Instinct & 0.1 & 0.07 & 0.05 \\
\hline
\end{tabular}


questionnaire followed the same format as the round one questionnaire. However, in the second-round questionnaire, expert participants were provided judgment criteria to evaluate the relative importance of 10 dimensions, using a series of pairwise comparisons, and the median of the score of each item was used to construct judgement matrices of the 10 dimensions by first author (see Fig. 2) [43]. Meanwhile, the number of subdimension and items are large, affects the judgement of experts. So, in this study, the average score of importance of each item minus the average score of other items from the second Delphi round was used to extract the intensity of importance (formula 3), then construct judgment matrices, Table 4 exhibits standard of pairwise comparison values for sub-dimensions and items [44]. According to formula 3 and standard of intensity of importance, we got the judgement matrices B subdimension of asthma knowledge (see Fig. 3).

$$
\mathrm{B}=\left(\mathrm{b}_{\mathrm{ij}}\right)_{\mathrm{n} \chi \mathrm{n}}\left(\mathrm{b}_{\mathrm{ij}}=\mathrm{b}_{\mathrm{i}}-\mathrm{b}_{\mathrm{j}}, \mathrm{i}, \mathrm{j}=1,2, \ldots, \mathrm{n}\right)
$$

The eigenvector of judgement matrix was calculated, and then the weight of each item was obtained.

\section{Round 3 of Delphi survey}

The third round of the Delphi survey ended in April, 2018. Eleven participants from the first round were invited and agreed to take part. Their ages ranging from 32 to 53 (mean $=41.00 ; \mathrm{SD}=6.55$ ) in round three. Table 5 exhibits the demographic data and characteristics of the expert participants who took part in the three rounds of the Delphi survey. The round-three questionnaires featured the format as the round-one and round-two questionnaires. The expert participants were asked to re-rate the importance of the items on the questionnaire, using the same 5-point Likert scale.

Participants remained anonymous to each other during the entire survey process, and they were required to complete the questionnaires within 3 weeks. Data collection was performed by the same member of the research team. All of the questionnaires and the data collection procedures were checked by the all members of the research team to assure credibility. The data was doubleentered and checked for accuracy.

\section{Data analysis}

Quantitative data were entered into Microsoft Excel 2010 and IBM SPSS 20.0 Statistics for Windows for analysis, and descriptive statistics were used. The rating for each item was analyzed and expressed as a mean value with standard deviation (SD). Following this, nonparametric statistics (e.g., chi-squared test of association) were used to determine the possibility of any response group bias. Coefficient of variation (CV) and Kendall's coefficient of concordance (Kendall's $W$ ) were used to test the dispersion of the participants' opinions. A $p$ value of less than 0.05 was considered statistically significant.

\section{Results}

\section{Survey results}

In round one of the Delphi survey, the authoritative coefficient for the expert participants ranged from 0.80 to 0.96 , with an average authority coefficient of 0.89 . The mean importance ratings for dimensions ranged from

$$
\mathrm{A}=\left(\begin{array}{cccccccccc}
1 & 1 / 3 & 1 & 3 & 1 & 1 & 3 & 1 & 1 & 1 \\
3 & 1 & 3 & 3 & 3 & 3 & 3 & 3 & 1 & 1 \\
1 & 1 / 3 & 1 & 1 & 1 & 1 & 3 & 1 & 1 & 1 \\
1 / 3 & 1 / 3 & 1 & 1 & 1 & 1 / 3 & 1 & 1 & 1 & 1 \\
1 & 1 / 3 & 1 & 1 & 1 & 1 & 1 & 1 & 1 & 1 \\
1 & 1 / 3 & 1 & 3 & 1 & 1 & 3 & 1 & 1 & 1 \\
1 / 3 & 1 / 3 & 1 / 3 & 1 & 1 & 1 / 3 & 1 & 1 & 1 / 3 & 1 / 3 \\
1 & 1 / 3 & 1 & 1 & 1 & 1 & 1 & 1 & 1 & 1 \\
1 & 1 & 1 & 1 & 1 & 1 & 3 & 1 & 1 & 1 \\
1 & 1 & 1 & 1 & 1 & 1 & 3 & 1 & 1 & 1
\end{array}\right)
$$

Fig. 2 Pairwise comparison matrix A for 10 dimensions 
Table 4 Standard of pairwise comparison values for sub-dimensions and items

\begin{tabular}{lll}
\hline & Definition & Intensity of importance \\
\hline $0.25<A_{i j}-A_{i k} \leq 0.50$ & $A_{i j}$ is moderately more important than $A_{i k}$ & 3 \\
$0.75<A_{i j}-A_{i k} \leq 1.00$ & $A_{i j}$ is strongly more important than $A_{i k}$ & 5 \\
$1.25<A_{i j}-A_{i k} \leq 1.50$ & $A_{i j}$ is very strongly more important than $A_{i k}$ & 7 \\
$1.75<A_{i j}-A_{i k}$ & $A_{i j}$ is extremely more important than $A_{i k}$ & 9 \\
Intermediate value between the two adjacent judgements & & $2,4,6,8$ \\
\hline
\end{tabular}

3.28 to 4.88 , and the coefficient of variation ranged from 0.07 to 0.37 . The mean importance ratings for subdimensions ranged from 3.20 to 4.86 , and the coefficient of variation ranged from 0.04 to 0.39 . The mean importance ratings for items ranged from 3.44 to 4.92 , and the coefficient of variation ranged from 0.06 to 0.32 . In round two, the participants' degree of authority ranged from 0.65 to 1.00 , with an average authority coefficient of 0.91 . The mean importance ratings for dimensions ranged from 4.00 to 4.92 , and the coefficient of variation ranged from 0.06 to 0.23 . The mean importance ratings for sub-dimensions ranged from 4.00 to 4.88 , and the coefficient of variation ranged from 0.07 to 0.26 . The mean importance ratings for items ranged from 3.54 to 4.83 , and the coefficient of variation ranged from 0.08 to 0.34 . In round three, the participants' degree of authority ranged from 0.67 to 0.98 , with an average authority coefficient of 0.90 . The mean importance ratings for the dimensions ranged from 4.36 to 4.91 , and the coefficient of variation ranged from 0.06 to 0.20 . The mean importance ratings for the sub-dimensions ranged from 4.27 to 4.91 , and the coefficient of variation ranged from 0.06 to 0.18 . The mean importance ratings for the items ranged from 4.45 to 4.91 , and the coefficient of variation ranged from 0.06 to 0.19 . After modification of the items in the questionnaire, the coordination results in the third round were acceptable-the Kendall's $W$ ranged from 0.654 to 0.693 (see Table 6).

\section{Item modifications}

Table 7 illustrates the requirements for consensus for all items in rounds 1, 2 and 3. Criteria reaching consensus were retained while those not reaching consensus were removed.

In round one of the Delphi survey, based on consensus criteria and team discussion, two dimensions were deleted, reward and threat was deleted because of its negative impact on patients, and natural consequences were deleted because of perceived duplication. Five of subdimensions (i.e., social reward, threat, information about health consequences, salience of consequences, and regulation) and 24 of items were deleted. An example for retaining items based on consensus criteria was shown in Table 8. In addition, the three dimensions were changed, improving the compliance was reworded as prompts, Asthma information was changed to asthma knowledge, and patient skills training was reworded as skills training for effective self-management because of its inaccurate language. Seven of sub-dimensions (i.e., prompts, the nature of asthma, management of comorbidities, peak flow meter usage, inhaler technique, identifying and avoiding

$$
\mathrm{B}=\left(\begin{array}{cccc}
1 & 1 / 3 & 1 / 2 & 2 \\
3 & 1 & 3 & 3 \\
2 & 1 / 3 & 1 & 2 \\
1 / 2 & 1 / 3 & 1 / 2 & 1
\end{array}\right)
$$

Fig. 3 Pairwise comparison matrix $B$ for sub-dimension of asthma knowledge 
Table 5 Demographic data and characteristics of the expert panel

\begin{tabular}{|c|c|c|c|}
\hline & $\begin{array}{l}\text { Round } 1(N=25) \\
N(\%)\end{array}$ & $\begin{array}{l}\text { Round } 2(N=24) \\
N(\%)\end{array}$ & $\begin{array}{l}\text { Round } 3(N=11) \\
N(\%)\end{array}$ \\
\hline \multicolumn{4}{|l|}{ Age (years) } \\
\hline$<40$ years old & $11(44.0)$ & $11(45.8)$ & $6(54.5)$ \\
\hline 40-50 years old & $10(40.0)$ & $9(37.5)$ & $3(27.3)$ \\
\hline$>50$ years old & $4(16.0)$ & $4(16.7)$ & $2(18.2)$ \\
\hline \multicolumn{4}{|l|}{ Work experience (years) } \\
\hline 10 years or less & $12(48.0)$ & $12(50.0)$ & $7(63.6)$ \\
\hline $10-20$ years & $10(40.0)$ & $9(37.5)$ & $2(18.2)$ \\
\hline More than 20 years & $3(12.0)$ & $3(12.5)$ & $2(18.2)$ \\
\hline \multicolumn{4}{|l|}{ Education } \\
\hline Bachelor's degree & $5(20.0)$ & $5(20.8)$ & $1(9.1)$ \\
\hline Master's degree & $13(52.0)$ & $10(41.7)$ & $7(63.6)$ \\
\hline $\mathrm{PhD}$ & $7(28.0)$ & $9(37.5)$ & $3(27.3)$ \\
\hline \multicolumn{4}{|l|}{ Professional Title } \\
\hline Intermediate title & $11(44.0)$ & $8(33.3)$ & $4(36.4)$ \\
\hline Senior vice title & $10(40.0)$ & $11(45.8)$ & $5(45.4)$ \\
\hline Senior title & $4(16.0)$ & $5(20.8)$ & $2(18.2)$ \\
\hline \multicolumn{4}{|l|}{ Affiliation } \\
\hline Educational institution & $6(24.0)$ & $5(20.8)$ & $5(45.5)$ \\
\hline Clinical practice & $19(76.0)$ & $19(79.2)$ & $6(54.5)$ \\
\hline
\end{tabular}

risk factors, good life style) and 42 of items were changed. Additionally, two new dimensions (i.e., ease of use and usability), eight new sub-dimensions (warnings, accessibility, automation, unconstraint, user-friendly interface, security, usefulness of knowledge, rate of update), and 15 new items were proposed by the participants to be added to the questionnaire after the first-round survey, which resulted in the inclusion of 10 dimensions, 25 sub-dimensions, and 73 items in the second-round questionnaire. Moreover, the wording of most items was revised based on the expert panel's comments and reordered the items concerning asthma self-management education and behavior change strategies.

Table 6 The concordance degree of the expert's opinions

\begin{tabular}{lllll}
\hline & Items & Kendall's $W$ & $X^{2}$ & $P$ \\
\hline Round 1 & Dimensions & 0.440 & 105.692 & $<0.001$ \\
& Sub-Dimensions & 0.410 & 226.335 & $<0.001$ \\
& Items & 0.412 & 859.754 & $<0.001$ \\
\multirow{2}{*}{ Round 2 } & Dimensions & 0.569 & 104.780 & $<0.001$ \\
& Sub-Dimensions & 0.548 & 239.506 & $<0.001$ \\
& Items & 0.507 & 758.071 & $<0.001$ \\
\multirow{2}{*}{ Round 3 } & Dimensions & 0.693 & 69.335 & $<0.001$ \\
& Sub-Dimensions & 0.654 & 150.503 & $<0.001$ \\
& Items & 0.656 & 413.448 & $<0.001$ \\
\hline
\end{tabular}

In round two, no new items were generated. Based on the criteria and team discussion, three of subdimensions (i.e., behavior substitution, unconstraint, and security) and 10 items were deleted. Three items were changed (Information released by apps can help patients to make decision was changed to The app can be easily accessed and obtained information.; The app can help patients to improve the efficiency of self-management was changed to Information released by apps is to patients' needs and value; The app can help patients to know the recent knowledge was changed to The app is updated regularly and timely) based on the suggestions of the expert participants. As a result, 10 dimensions, 23 subdimensions, and 63 items were generated for the second round of the Delphi survey. In addition, we added descriptions and/or examples for items in the questionnaire.

In round three, only one item (i.e., the app allows users to re-set the goals based on patients' health data) was deleted because difficult to be measured. As a result, the final version of asthma apps assessment framework

Table 7 Requirements for consensus in rounds 1, 2 and 3

\begin{tabular}{llll}
\hline Criterion & Round 1 & Round 2 & Round 3 \\
\hline Percentage important & $\geq 42 \%$ & $\geq 44 \%$ & $\geq 65 \%$ \\
Mean importance rating & $\geq 4.09$ & $\geq 4.21$ & $\geq 4.53$ \\
Coefficient of variation & $<0.23$ & $<0.20$ & $<0.16$ \\
\hline
\end{tabular}


Table 8 An example for retaining items based on the requirements for consensus in round one

\begin{tabular}{lllll}
\hline Dimension & Mean & CV & The percentage important & Decision \\
\hline Asthma knowledge & 4.80 & 0.083 & $80 \%$ & Remaining \\
Reward and threat & 3.28 & 0.371 & $20 \%$ & Removed \\
Social support & 4.08 & 0.229 & $40 \%$ & Remaining after discussion \\
Criterion & $\geq 4.09$ & $<0.23$ & $\geq 42 \%$ & \\
\hline
\end{tabular}

comprised 10 dimensions, 23 sub-dimensions, and 62 items after three Delphi surveys. See Table 9.

\section{Calculating the weight of items through AHP}

In round two, the weights of the dimensions were 0.105 , $0.203,0.094,0.068,0.084,0.105,0.049,0.084,0.105$, 0.105 , respectively, with a CR of 0.037 . The overall weights of the sub-dimensions ranged from 0.015 to 0.135 , with $\mathrm{CR}$ values from 0 to 0.062 . Moreover, the overall weights of the items ranged from 0.002 to 0.079 , with $\mathrm{CR}$ values ranging from 0 to 0.046 .

\section{Discussion}

Much of the literature concerning the evaluation of mHealth apps has merely addressed the technical aspects of apps [45-49]. The purpose of this study was to develop a framework to assess and improve the quality of asthma smartphone apps for use on smartphones. The three-round Delphi survey process produced consensus on the items comprising a framework for assessing the quality of asthma apps, from the perspective of both asthma self-management education and behavior change strategies. The framework features 10 dimensions and corresponding items, which reflect the material content of asthma apps currently available for download on smartphones. This framework is an important first step in using asthma apps as part of the set of strategies available to healthcare providers to improve quality of life (QOL) among asthmatics.

Through the three-round Delphi survey process, the number of items to be included in the assessment framework was reduced from 87 to 62 , by merging overlapping items and deleting items that would be difficult to operationalize and measure, based on feedback. Asthma self-management should address asthma knowledge, skills training for effective self-management, nonpharmacological interventions, goals and planning, feedback and monitoring, shaping knowledge, social support, and prompts (i.e., brief messages that encourage the user to engage in particular behaviors).

Among the dimensions, skills training for effective selfmanagement had the highest weight (0.203), followed by asthma knowledge (0.105), shaping knowledge (0.105), ease of use (0.105) and usability (0.105). Therefore, skills training for effective self-management is the most important factor in asthma self-management, from the perspective of participating experts and consistent with the literature [50, 51]. Moreover, reports of web-based interventions have shown that interventions involving more behavior change techniques are indeed effective [52].

The framework can be used to create an evaluation instrument which could then be tried out and evaluated itself for validity and reliability.

\section{Limitations}

This study identified a framework and a needed next step would be to derive and validate an actual instrument. The framework only reflects the judgement of the participants' choosen and that another group, perhaps in another country or composed of more multidisciplinary experts, might produce a different framework. The fact that participants were all asthma experts explains why the framework's content is so heavily focused on the disease and its treatment and why an essential item for all health related apps like privacy and security is missing. Cost, software reliability, and whether patients understand the information apps present might be concerns of those in the telemedicine field. While ease of use may touch upon this, another telemedicine concern flowing from understandability is how much knowledge apps assume patients have.

In addition, the whole research was conducted in China (a middle-income Asian nation). The sample size was small, leading to many semi-qualitative results. Also, the path for future research in applying the framework in culturally diverging regions of lower (e.g. sub-Saharan Africa) and/or higher (e.g. Europe) exists. The framework designed surveyed providers (and not patients) about what they think is good for patients. Future research might include an analogous methodology used with severely affected ("expert") asthma patients, etc. Still, the current framework provides guidance for assessing asthma content and behavioral strategies in existing apps on developing new one.

\section{Conclusion}

This study involved 29 experts who were active in respiratory disease field for more than 5 years. The 
Table 9 Asthma apps assessment framework and weight value of each item after three-round Delphi survey

\begin{tabular}{|c|c|c|c|c|}
\hline Dimensions & Weight & Sub-Dimensions & Weight & Items \\
\hline \multicolumn{5}{|c|}{ The following knowledge is included in the apps (i.e., presented in words, pictures, video, etc.) } \\
\hline Asthma knowledge & 0.105 & $\begin{array}{l}\text { Basic fact about } \\
\text { asthma }\end{array}$ & 0.182 & Definition of asthma \\
\hline
\end{tabular}

Criteria/Example

Asthma is a chronic

Causes of asthma

Asthma is caused by a combination of endogenous (genetic) and external (environment) causes

Respiratory symptoms of asthma

Repeated episodes of heeze, shortness of breath, chest tightness and cough

Prognosis of asthma

Asthma cannot be cured, but can be effectively controlled through effective management

Early treatment

Early controller treatment of asthma is critical to achieving optimal outcomes

Categories of asthma medications

Asthma medications include controller medications and reliever medications

Roles and usage of controller medications

Controller medications can be used to reduce airway inflammation, control symptoms, and reduce future risks, which must be used regularly

Roles and usage of reliever medications

Reliever medications can

be used to relief breakthrough symptoms, which must be used as needed

Side-effects of asthma medications

Local side effects of ICS include oral thrush and dysphonia; osteoporosis, hypertension, and diabetes, etc. in high dose steroids; tachycardia and tremor in $\mathrm{B}_{2}$-agoinsts

Carrying reliever medications

Patients need to carry asthma reliever medications (such as Ventolin solution) with them in case of emergency

Management of asthma exacerbations

0.241 Early signs and symptoms of worsening asthma

Symptoms of asthma exacerbations
The app describes early signs and symptoms of worsening asthma (sneezing, runny nose, dry cough, shortness of breath, and chest tightness, etc.)

The app describes symptoms of asthma exacerbations (a progressive increase in
$0.253 \quad 0.0048$ 
Table 9 Asthma apps assessment framework and weight value of each item after three-round Delphi survey (Continued)

\begin{tabular}{|c|c|c|c|c|c|c|c|}
\hline Dimensions & Weight & Sub-Dimensions & Weight & Items & Criteria/Example & Weight & $\begin{array}{l}\text { Overall } \\
\text { Weight }\end{array}$ \\
\hline & & & & & $\begin{array}{l}\text { symptoms of shortness of } \\
\text { breath, cough, wheezing } \\
\text { or chest tightness) }\end{array}$ & & \\
\hline & & & & $\begin{array}{l}\text { Management of asthma } \\
\text { exacerbations }\end{array}$ & $\begin{array}{l}\text { For example, patients were } \\
\text { removed from the allergen } \\
\text { environment, inhale } B_{2} \\
\text { agonist, and went to see } \\
\text { the doctor in time }\end{array}$ & 0.391 & 0.0098 \\
\hline & & & & $\begin{array}{l}\text { Management after asthma } \\
\text { exacerbations }\end{array}$ & $\begin{array}{l}\text { Seek the cause of acute } \\
\text { attack actively, check } \\
\text { medication compliance, } \\
\text { and adjust treatment plan }\end{array}$ & 0.276 & 0.0070 \\
\hline & & $\begin{array}{l}\text { Asthma with } \\
\text { comorbidities } \\
\text { and triggers }\end{array}$ & 0.138 & Comorbidities of asthma & $\begin{array}{l}\text { The app describes } \\
\text { comorbidities of asthma, } \\
\text { such as, rhinitis, sinusitis, } \\
\text { and symptomatic } \\
\text { gastroesophageal reflux } \\
\text { disease, etc. }\end{array}$ & 0.249 & 0.0036 \\
\hline & & & & $\begin{array}{l}\text { Management of } \\
\text { comorbidities }\end{array}$ & $\begin{array}{l}\text { The app provides details of } \\
\text { treatment of rhinitis, } \\
\text { sinusitis, and symptomatic } \\
\text { gastroesophageal reflux } \\
\text { disease, and psychological } \\
\text { intervention, etc. }\end{array}$ & 0.157 & 0.0023 \\
\hline & & & & Triggers of asthma & $\begin{array}{l}\text { The app describes triggers } \\
\text { of asthma, such as, } \\
\text { occupational factors, } \\
\text { environmental factors, } \\
\text { weather changes, drug } \\
\text { and sports }\end{array}$ & 0.594 & 0.0086 \\
\hline \multirow[t]{7}{*}{$\begin{array}{l}\text { Skills training for } \\
\text { effective self- } \\
\text { management }\end{array}$} & \multirow[t]{7}{*}{0.203} & $\begin{array}{l}\text { Peak flow meter use } \\
\text { and monitoring }\end{array}$ & 0.667 & $\begin{array}{l}\text { The purpose of using peak } \\
\text { flow meter }\end{array}$ & $\begin{array}{l}\text { A peak flow meter is used } \\
\text { for monitoring lung } \\
\text { function changes in } \\
\text { patients }\end{array}$ & 0.195 & 0.0264 \\
\hline & & & & $\begin{array}{l}\text { Operational criteria for } \\
\text { peak flow meter }\end{array}$ & $\begin{array}{l}\text { Take a deep breath, seal } \\
\text { your mouth tightly around } \\
\text { the mouthpiece and then } \\
\text { blow as hard and as fast as } \\
\text { you soon. Check the } \\
\text { number, re-set the pointer } \\
\text { to zero, and repeat two } \\
\text { more times }\end{array}$ & 0.391 & 0.0527 \\
\hline & & & & The same peak flow meter & $\begin{array}{l}\text { The patient should use the } \\
\text { same peak flow meter } \\
\text { each time }\end{array}$ & 0.276 & 0.0373 \\
\hline & & & & $\begin{array}{l}\text { The best time to use peak } \\
\text { flow meter }\end{array}$ & $\begin{array}{l}\text { PEF is measured in the } \\
\text { morning, and then in the } \\
\text { evening (after } 10-12 \mathrm{~h} \text { of } \\
\text { the first time) }\end{array}$ & 0.138 & 0.0186 \\
\hline & & Inhaler devices use & 0.333 & Common inhaler devices & $\begin{array}{l}\text { The app describes } \\
\text { common inhaler devices, } \\
\text { such as pressurized } \\
\text { metered dose inhalers } \\
\text { (pMDI), pMDI +spacer and } \\
\text { dry power inhalers (DPIs) }\end{array}$ & 0.140 & 0.0094 \\
\hline & & & & $\begin{array}{l}\text { The importance of correct } \\
\text { inhaler technique }\end{array}$ & $\begin{array}{l}\text { Correct inhaler technique } \\
\text { can enhance the } \\
\text { medication into lung, } \\
\text { reduce asthma attack, and } \\
\text { obtain the best clinical effect }\end{array}$ & 0.528 & 0.0356 \\
\hline & & & & Operational criteria for & For example, usage of & 0.332 & 0.0225 \\
\hline
\end{tabular}


Table 9 Asthma apps assessment framework and weight value of each item after three-round Delphi survey (Continued)

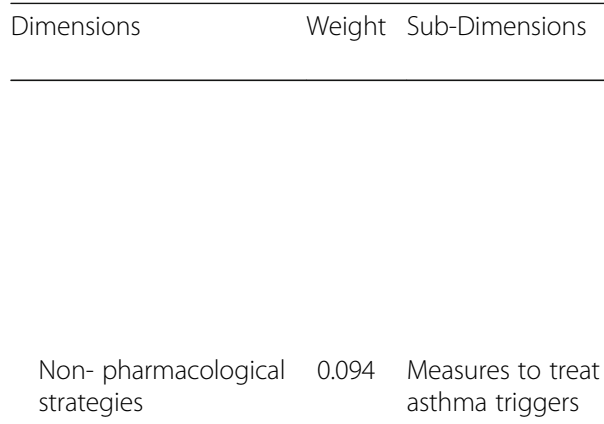

Lifestyles

Weight Items
different inhaler devices
0.667 Identifying risk factors that
make asthma worse

Avoidance of environmental smoke exposure

Avoidance of occupation exposures

Avoidance of medications that may make asthma worse

Avoidance of allergen exposure

Avoidance of indoor and outdoor air pollution

0.333 Avoidance of emotional stress

Regular moderate physical activity

The following behavioral change strategies are employed in apps:

Goals and planning 0.068 Goal setting (outcome/
Action plans

0.333 Explain the purpose of an

Criteria/Example

Weight Overall

Weight

Diskus is that remove mouthpiece cover, position inhaler mouthpiece in mouth and seal lips, inward breath steady and deeply, remove inhaler, hold breath for a few seconds, and rinse mouth

The app describes factors that make asthma worse, such as allergens exposure, physical and chemical irritants, psychosocial factors, etc.

The app provides advice about avoidance of active smoking and passive smoking

The app provides advice about avoidance of plant dust, animal dust, etc.

The app provides advice about avoidance of aspirin, NSAIDs, and ß-blockers,

etc.

The app provides advice about avoidance of domestic mites, furred animals, fungi, and pollen, etc.

$0.160 \quad 0.0100$

$0.106 \quad 0.0066$

The app provides advice about avoidance of domestic coal burning, cooking, and traffic pollution, etc.

The app provides advice about relieving emotional stress and encouraging breathing exercises, etc.

Patients should exercise regularly and given appropriate exercise advice asthma action plan

Allow making individualized asthma action plan, and updated

Allows users to set outcome goals or provide outcome goals

Allow users to set behavior goals or provide behavior goals

The app allows users to record symptoms and PEF values daily, and assess asthma control level periodically, etc.

The app allows users to set the goals of asthma control

An asthma action plan helps patients to identify early symptoms of asthma attacks and respond appropriately to improve asthma control

The app allows doctors to program asthma action plan directly into their 
Table 9 Asthma apps assessment framework and weight value of each item after three-round Delphi survey (Continued)

\begin{tabular}{|c|c|c|c|c|}
\hline Dimensions & Weight & Sub-Dimensions & Weight & Items \\
\hline & & & & in time \\
\hline \multirow[t]{2}{*}{$\begin{array}{l}\text { Feedback and } \\
\text { monitoring }\end{array}$} & 0.084 & Feedback & 0.250 & $\begin{array}{l}\text { Provide result feedback } \\
\text { information based on } \\
\text { patients' health data }\end{array}$ \\
\hline & & & & $\begin{array}{l}\text { Provide professional } \\
\text { feedback information } \\
\text { based on patients' inhaler } \\
\text { technique }\end{array}$ \\
\hline
\end{tabular}

Provide feedback information based on patients' changing asthma status

Allow storing and summarizing patients' recent health data, and generating summary visualization automatically

Allow connecting medical devices or wearables to upload data and provide feedback information to patients

Self-monitoring of behavior

Self-monitoring of outcomes of behavior

Provide a diary to record patients' symptoms.

Provide a diary to record medication.

Provide a diary to record return visit.

0.250 Provide a diary to record lung function test.

Criteria/Example
phone or users type in
manually

The app can provide advice based on changing

PEF, symptoms or ACT scores

The app allows users to upload the patients' inhaler technique video through user-end, and then clinicians check inhaler technique in order to identify problematic steps

The app can provide feedback about severity of asthma based on symptoms or PEF, etc.

The app allows storing patients' data, such as symptoms, PEF or medicine use

For example, after the sensor collecting the patients' vital signs, the app can send the data to end-users and judge whether the patients' health is in the normal range

The app allows users to type in manually or supports pair to the patients' Bluetooth device automatically for data exchange

The app provides a diary to record details about wheezing/shortness of breath/sleep, etc.

The app provides a diary to record details about medication use, such as categories and frequency, etc

The app provides a diary to record details about return visit, such as frequency and results, etc.

The app provides a diary to record details about lung function test, such as $\mathrm{FEV}_{1}, F V C$, etc.

Provide a diary to record worsening asthma-related events.
The app provides a diary to record details about worsening asthma-related events, such as attack symptoms, duration of symptoms, and complications, etc. 
Table 9 Asthma apps assessment framework and weight value of each item after three-round Delphi survey (Continued)

\begin{tabular}{|c|c|c|c|c|c|c|c|}
\hline Dimensions & Weight & Sub-Dimensions & Weight & Items & Criteria/Example & Weight & $\begin{array}{l}\text { Overall } \\
\text { Weight }\end{array}$ \\
\hline & & & & $\begin{array}{l}\text { Provide asthma assessment } \\
\text { tools }\end{array}$ & $\begin{array}{l}\text { The app provides asthma } \\
\text { assessment tools to assess } \\
\text { patient progress, such as } \\
\text { Asthma Control Test (ACT) }\end{array}$ & 0.493 & 0.0104 \\
\hline \multirow[t]{2}{*}{ Shaping knowledge } & 0.105 & $\begin{array}{l}\text { Demonstration of } \\
\text { behavior }\end{array}$ & 1.000 & $\begin{array}{l}\text { Provide video tutorials or } \\
\text { animations of peak flow } \\
\text { meter use }\end{array}$ & $\begin{array}{l}\text { The app provides video } \\
\text { tutorials or animations to } \\
\text { display instructions of peak } \\
\text { flow meter for patients }\end{array}$ & 0.500 & 0.0524 \\
\hline & & & & $\begin{array}{l}\text { Provide video tutorials } \\
\text { or animations of inhaler } \\
\text { devices use }\end{array}$ & $\begin{array}{l}\text { The app provides video } \\
\text { tutorials or animations to } \\
\text { display instructions of } \\
\text { inhaler device for patients }\end{array}$ & 0.500 & 0.0524 \\
\hline \multirow[t]{2}{*}{ Social support } & 0.049 & Practical support & 0.667 & $\begin{array}{l}\text { Allow establishing a } \\
\text { cooperative relationship } \\
\text { between doctors and } \\
\text { patients, and providing } \\
\text { patient-doctor } \\
\text { communication platform } \\
\text { or interactive consultation } \\
\text { service }\end{array}$ & $\begin{array}{l}\text { For example, the app } \\
\text { offers online consulting } \\
\text { service }\end{array}$ & 0.100 & 0.0324 \\
\hline & & Emotional support & 0.333 & $\begin{array}{l}\text { Provide functions of } \\
\text { interactive communication } \\
\text { among patients }\end{array}$ & $\begin{array}{l}\text { For example, the app } \\
\text { provides functions of } \\
\text { sharing information and } \\
\text { comment, etc. }\end{array}$ & 0.100 & 0.0162 \\
\hline \multirow[t]{5}{*}{ Prompts } & 0.084 & Reminder & 0.333 & $\begin{array}{l}\text { Allow users to set } \\
\text { reminders for asthma tests. }\end{array}$ & $\begin{array}{l}\text { The app provides details of } \\
\text { asthma tests reminder }\end{array}$ & 0.139 & 0.0039 \\
\hline & & & & $\begin{array}{l}\text { Allow users to set } \\
\text { medication reminder }\end{array}$ & $\begin{array}{l}\text { The app provides details of } \\
\text { medication reminder, such } \\
\text { as medication name and } \\
\text { dosage, etc. }\end{array}$ & 0.393 & 0.0110 \\
\hline & & & & $\begin{array}{l}\text { Allow users to set } \\
\text { reminders for return visit }\end{array}$ & $\begin{array}{l}\text { The app can send } \\
\text { information regularly to } \\
\text { remind return visit }\end{array}$ & 0.234 & 0.0066 \\
\hline & & & & $\begin{array}{l}\text { Provide reminders for } \\
\text { checking inhalers }\end{array}$ & $\begin{array}{l}\text { The app provides } \\
\text { reminders for checking the } \\
\text { date and medications } \\
\text { dosage of inhalers }\end{array}$ & 0.234 & 0.0066 \\
\hline & & Warnings & 0.667 & $\begin{array}{l}\text { Provide alert based on } \\
\text { patients' changing health } \\
\text { data }\end{array}$ & $\begin{array}{l}\text { The app can send warning } \\
\text { information automatically } \\
\text { when there is abnormal } \\
\text { data }\end{array}$ & 1.000 & 0.0561 \\
\hline \multicolumn{8}{|c|}{ The following design principles are implemented in the apps: } \\
\hline \multirow[t]{3}{*}{ Ease of use } & 0.105 & Accessibility & 0.429 & $\begin{array}{l}\text { The app can be easily } \\
\text { accessed and obtained } \\
\text { information }\end{array}$ & $\begin{array}{l}\text { The app and its contents } \\
\text { are accessible to all users } \\
\text { (including all kinds of users } \\
\text { with access barriers, such } \\
\text { as visual impairment, } \\
\text { hearing impairment, etc.) }\end{array}$ & 1.000 & 0.0449 \\
\hline & & Automation & 0.429 & $\begin{array}{l}\text { The app can retrieve } \\
\text { patients' data automatically }\end{array}$ & $\begin{array}{l}\text { The app can connect to } \\
\text { health apparatuses to } \\
\text { improve efficiency of data } \\
\text { collection }\end{array}$ & 1.000 & 0.0449 \\
\hline & & User-friendly interface & 0.142 & $\begin{array}{l}\text { All components/screens, } \\
\text { menu labels/icons of apps } \\
\text { are clear, intuitive, and able } \\
\text { to use immediately }\end{array}$ & $\begin{array}{l}\text { Interface design (including } \\
\text { menu, background, colors, } \\
\text { fonts, etc.) is scientific and } \\
\text { reasonable. The operation } \\
\text { steps are simple and can } \\
\text { be operated according to } \\
\text { window prompts without } \\
\text { user guide. Navigation is }\end{array}$ & 1.000 & 0.0150 \\
\hline
\end{tabular}


Table 9 Asthma apps assessment framework and weight value of each item after three-round Delphi survey (Continued)

\begin{tabular}{|c|c|c|c|c|c|c|c|}
\hline Dimensions & Weight & Sub-Dimensions & Weight & Items & Criteria/Example & Weight & $\begin{array}{l}\text { Overall } \\
\text { Weight }\end{array}$ \\
\hline & & & & & $\begin{array}{l}\text { logical and intuitive, and } \\
\text { internal and external links } \\
\text { are valid }\end{array}$ & & \\
\hline \multirow[t]{2}{*}{ Usability } & 0.105 & $\begin{array}{l}\text { Usefulness of } \\
\text { knowledge }\end{array}$ & 0.250 & $\begin{array}{l}\text { Information released by } \\
\text { apps is for patient's needs } \\
\text { and value }\end{array}$ & $\begin{array}{l}\text { Information contained } \\
\text { within apps is accurate } \\
\text { and comprehensive, with } \\
\text { high utilization rate }\end{array}$ & 1.000 & 0.0262 \\
\hline & & Rate of update & 0.750 & $\begin{array}{l}\text { The app is updated } \\
\text { regularly and timely }\end{array}$ & $\begin{array}{l}\text { The app (including its } \\
\text { contents, functions and } \\
\text { technology) is updated } \\
\text { regularly and timely }\end{array}$ & 1.000 & 0.0786 \\
\hline
\end{tabular}

assessment framework created can be used to develop evaluation instruments for asthma apps that can be used by health researchers and healthcare professionals wishing to incorporate them in their treatment plans and to guide the development of quality asthma apps supporting patient self-management. Among them, portion of behavior change strategies of the framework can be used in evaluation of HIT apps for other chronic and common disorders.

\section{Abbreviations}

AHP: Analytic hierarchy process; apps: applications; BCT: Behavior change techniques; Cl: Consistency index; CNKI: China National Knowledge Infrastructure; CNNIC: China Internet Network Information Center; CR: Consistency ratio; CV: Coefficient of variation; QOL: Quality of life; RCl: Random consistency index; SD: Standard deviation

\section{Acknowledgments}

The authors thank EdD Brian Greene, University of Pittsburgh, for his proofreading and valuable suggestions.

\section{Authors' contributions}

YLW designed the study protocol. ZFG and LS performed the literature research. ZFG, YLW, LS, and QX designed the instrument for data collection, performed data organization and analysis, and contacted the expert participants for the Delphi survey. ZFG, LS, and YLW drafted the manuscript YLW and LS revised the manuscript. All authors approved the final version.

\section{Funding}

No grants from any funding agency were received in this research project.

\section{Availability of data and materials}

The dataset supporting the conclusions of this article is not available since the privacy of residents is included.

\section{Ethics approval and consent to participate}

The Ethics Committee of Capital Medical University confirmed that no formal Ethics vote or consent is needed for this project. Participants were informed that participation was on a voluntary basis and that their anonymity was guaranteed. A questionnaire was provided to each participant, within which they were informed that submission of their responses would be considered as proof of consent to participate.

\section{Consent for publication}

Not applicable.

\section{Competing interests}

The authors declare that they have no competing interests.
Received: 16 April 2019 Accepted: 1 October 2019

Published online: 15 October 2019

\section{References}

1. (*NEW) 2018 GINA Report: Global Strategy for Asthma Management and Prevention | Global Initiative for Asthma - GINA [http://ginasthma.org/2018gina-report-global-strategy-for-asthma-management-and-prevention/].

2. Ahmetaj LN. The Global Asthma Report 2014. Auckland: Global Asthma Network; 2014.

3. Wong GW, Kwon N, Hong JG, Hsu JY, Gunasekera KD. Pediatric asthma control in Asia: phase 2 of the asthma insights and reality in Asia-Pacific (AIRIAP 2) survey. Allergy. 2013;68(4):524-30.

4. Masoli M, Fabian D, Holt S, Beasley R. The global burden of asthma: executive summary of the GINA dissemination committee report. Allergy. 2004:59(5):469-78

5. Gibson PG, Powell H. Written action plans for asthma: an evidence-based review of the key components. Thorax. 2004:59(2):94-9.

6. Gardner A, Kaplan B, Brown W, Krier-Morrow D, Rappaport S, Marcus L, Conboy-Ellis K, Mullen A, Rance K, Aaronson D. National standards for asthma self-management education. Ann Allergy Asthma Immunol. 2015; 114(3):178-186.e171.

7. Welsh EJ, Hasan M, Li P. Home-based educational interventions for children with asthma. Cochrane Database Syst Rev. 2011;66(10):CD008469.

8. Morrison D, Mair FS, Yardley L, Kirby S, Thomas M. Living with asthma and chronic obstructive airways disease: Using technology to support selfmanagement - an overview. Chron Respir Dis. 2016;14:407-19 (4\%\2018-0423 22:13:00).

9. Huckvale K, Morrison C, Ouyang J, Ghaghda A, Car J. The evolution of mobile apps for asthma: an updated systematic assessment of content and tools. BMC Med. 2015:13(1):58.

10. McLean G, Murray E, Band R, Moffat KR, Hanlon P, Bruton A, Thomas M, Yardley L, Mair FS. Interactive digital interventions to promote selfmanagement in adults with asthma: systematic review and meta-analysis. BMC Pulmonary Med. 2016;16(1):83.

11. CNNIC [http://www.cnnic.cn/gywm/xwzx/rdxw/201708/t20170804_69449. htm.]

12. Research 2 Guidance. mHealth App Developer Economics 2016. The current status and trends of the mhealth app market. 2016. http://research2 guidance.com/r2g/r2g-mHealth-App-Developer-Economics-2016.pdf

13. GPs to 'Prescribe' Apps for Patients. Best Health Apps and Ideas to Revolutionise NHS for Patients. [https://www.gov.uk/government/news/gpsto-prescribe-apps-for-patients].

14. Demidowich AP, Lu K, Tamler R, Bloomgarden Z. An evaluation of diabetes self-management applications for android smartphones. J Telemed Telecare. 2012;18(4):235-8.

15. N.Y. attorney general nets penalties from health apps for misleading consumers - Modern Healthcare [http://www.modernhealthcare.com/ article/20170323/NEWS/170329949].

16. Bastawrous A, Armstrong MJ. Mobile health use in low- and high-income countries: an overview of the peer-reviewed literature. J R Soc Med. 2013: 106(4):130-42.

17. Rosser BA, Eccleston C. Smartphone applications for pain management. J Telemed Telecare. 2011;17(6):308-12. 
18. Pandey A, Hasan S, Dubey D, Sarangi S. Smartphone apps as a source of cancer information: changing trends in health information-seeking behavior. J Cancer Educ. 2013;28(1):138-42.

19. Buijink AW, Visser BJ, Marshall L. Medical apps for smartphones: lack of evidence undermines quality and safety. Evid Based Med. 2013;18(3):90-2.

20. Powell $A C$, Landman $A B$, Bates DW. In search of a few good apps. JAMA. 2014;311(18):1851-2.

21. Chan S, Torous J, Hinton L, Yellowlees P. Towards a framework for evaluating mobile mental health apps. Telemed J E Health. 2015;21(12): 1038-41.

22. Huckvale K, Car M, Morrison C, Car J. Apps for asthma self-management: a systematic assessment of content and tools. BMC Med. 2012;10(1):144

23. Tinschert $P$, Jakob R, Barata F, Kramer JN, Kowatsch T. The potential of mobile apps for improving asthma self-management: a review of publicly available and well-adopted asthma apps. JMIR Mhealth Uhealth. 2017;5(8): e113.

24. Ju QY, Huang LH, Zhao XH, Xing MY, Shao LW, Zhang MY, Shao RY. Development of evidence-based nursing-sensitive quality indicators for emergency nursing: a Delphi study. J Clin Nurs. 2018;27:3008-19.

25. Hasson F, Keeney S, McKenna H. Research guidelines for the Delphi survey technique. J Adv Nurs. 2000;32(4):1008-15.

26. Hsu CC, Sandford BA. The Delphi technique: making sense of consensus. Pract Assess Res Eval. 2007:26(10):289-304.

27. Wu YL. Study on the index system of assessment in maternal and child health of counties in Sichuan province. Sichuan University: Master's thesis: 2005.

28. Saaty TL. How to make a decision: the analytic hierarchy process. Eur J Oper Res. 1994:48(1):9-26.

29. Triantaphyllou E, Mann SH. Using the analytic hierarchy process for decision making in engineering applications: some challenges. Int J Ind Eng App Pract. 1995;2:35-44.

30. Guan ZF, Xiao Q, Sun L, Wang YL. Research on quality evaluation of bronchial asthma management application based on content analysis. Chin Nurs Res. 2018:32(12):1885-90.

31. Michie S, Richardson M, Johnston M, Abraham C, Francis J, Hardeman W, Eccles MP, Cane J, Wood CE. The behavior change technique taxonomy (v1) of 93 hierarchically clustered techniques: building an international consensus for the reporting of behavior change interventions. Ann Behav Med. 2013;46(1):81-95

32. 2016 GINA Report, Global Strategy for Asthma Management and Prevention [http://ginasthma.org/2016-gina-report-global-strategy-for-asthmamanagement-and-prevention/].

33. Michie S, Hyder N, Walia A, West R. Development of a taxonomy of behaviour change techniques used in individual behavioural support for smoking cessation. Addict Behav. 2011;36(4):315-9.

34. Abraham C, Michie S. A taxonomy of behavior change techniques used in interventions. Health Psychol. 2008;27(3):379-87.

35. Michie S, Johnston M, Francis J, Hardeman W, Eccles M. From theory to intervention: mapping theoretically derived behavioural determinants to behaviour change techniques. Appl Psychol. 2008;57(4):660-80.

36. Michie S, Ashford S, Sniehotta FF, Dombrowski SU, Bishop A, French DP. A refined taxonomy of behaviour change techniques to help people change their physical activity and healthy eating behaviours: the CALO-RE taxonomy. Psychol Health. 2011;26(11):1479-98.

37. Reddy AP, Gupta MR. Management of asthma: the current US and European guidelines. Adv Exp Med Biol. 2014;795:81-103.

38. Odom L, Christenbery T. There is an "app" for that: designing mobile phone technology to improve asthma action plan use in adolescent patients. J Am Assoc Nurse Pract. 2016;28(11):583-90.

39. Jia G, Yang P, Zhou J, Zhang H, Lin C, Chen J, Cai G, Yan J, Ning G. A framework design for the $\mathrm{mHealth}$ system for self-management promotion. Biomed Mater Eng. 2015;26(Suppl 1):S1731-40.

40. Stoyanov SR, Hides L, Kavanagh DJ, Zelenko O, Tjondronegoro D, Mani M. Mobile app rating scale: a new tool for assessing the quality of health mobile apps. JMIR Mhealth Uhealth. 2015;3(1):e27.

41. Brown BB. Delphi process: a methodology used for the elicitation of opinions of experts. Santa Monica: RAND Corp; 1968.

42. Guo XH. Medical field investigation techniques and statistical analysis. Beijing: People's Medical Publishing House Co., LTD; 2009

43. Sun ZQ, Wang LS. Comprehensive evaluation method and its application in medicine. Beijing: People's Medical Publishing House Co., LTD; 2014
44. Zhang $X$, Chen $X$, Duan PB, Zhang YY. Construction of an appraisal system of clinical synthetical competence for nursing undergraduates based on delphi method and analytic hierarchy process. Nursing J Chinese Peoples Liberation Army. 2012:3:12-14,45.

45. Martínez-Pérez B, Torre-Díez IDL, López-Coronado M. Experiences and results of applying tools for assessing the quality of a mHealth app named heartkeeper. J Med Syst. 2015;39(11):142.

46. Hale K, Capra S, Bauer J. A framework to assist health professionals in recommending high-quality apps for supporting chronic disease selfmanagement: illustrative assessment of type 2 diabetes apps. Jmir Mhealth Uhealth. 2015;3(3):e87.

47. Reynoldson C, Stones C, Allsop M, Gardner P, Bennett MI, Closs SJ, Jones R, Knapp P. Assessing the quality and usability of smartphone apps for pain self-management. Pain Med. 2014;15(6):898-909.

48. Wu AC, Carpenter JF, Himes BE. Mobile health applications for asthma. J Allergy Clin Immunol Pract. 2015;3(3):446-448.e416.

49. Mobile Medical Applications-Guidance for Industry and Food and Drug Administration Staff. US Food and Drug Administration 2015

50. Walsh JC, Teresa C, Michael H, Jim D, Abra MN. An mHealth intervention using a smartphone app to increase walking behavior in young adults: a pilot study. Jmir Mhealth Uhealth. 2016;4(3):e109.

51. Maher C, Ferguson M, Vandelanotte C, Plotnikoff R, Bourdeaudhuij ID, Thomas S, Nelsonfield K, Olds T. A web-based, social networking physical activity intervention for insufficiently active adults delivered via facebook app: randomized controlled trial. J Med Internet Res. 2015;17(7):e174.

52. Genugten LV, Dusseldorp E, Webb TL, Empelen PV. Which combinations of techniques and modes of delivery in internet-based interventions effectively change health behavior? A meta-analysis. J Med Internet Res. 2016;18(6): e155.

\section{Publisher's Note}

Springer Nature remains neutral with regard to jurisdictional claims in published maps and institutional affiliations.
Ready to submit your research? Choose BMC and benefit from:

- fast, convenient online submission

- thorough peer review by experienced researchers in your field

- rapid publication on acceptance

- support for research data, including large and complex data types

- gold Open Access which fosters wider collaboration and increased citations

- maximum visibility for your research: over $100 \mathrm{M}$ website views per year

At BMC, research is always in progress.

Learn more biomedcentral.com/submissions 